\title{
Precocious glucocorticoid exposure reduces skeletal muscle satellite cells in the fetal rat
}

\author{
Ganga Gokulakrishnan ${ }^{1,2}$, Xiaoyan Chang', Ryan Fleischmann'1 and Marta L Fiorotto' \\ IUSDA/ARS Children's Nutrition Research Center, Department of Pediatrics, Baylor College of Medicine, \\ Houston, Texas, USA \\ 2Department of Pediatrics, Texas Children's Hospital, Baylor College of Medicine, Houston, Texas, USA
}

Correspondence should be addressed to M L Fiorotto Email martaf@bcm.edu

\begin{abstract}
Perinatal skeletal muscle growth rates are a function of protein and myonuclear accretion. Precocious exposure of the fetus to glucocorticoids (GLC) in utero impairs muscle growth. Reduced muscle protein synthesis rates contribute to this response, but the consequences for myonuclear hyperplasia are unknown. To test the hypothesis that blunting of Pax7+ muscle progenitor cell proliferative activity by GLC in vivo also contributes to reduced fetal muscle growth, pregnant rats were administered dexamethasone (DEX: $1 \mathrm{mg} / \mathrm{L}$ drinking water) from embryonic day (ED) 13 to ED21. Their responses were compared to pair-fed (PF) and ad libitum-fed controls (CON). Bromodeoxyuridine (BrdU) was administered before delivery to measure myonuclear accretion. Fetal hind limb and diaphragm muscles were collected at term and analyzed for myofiber cross-sectional area (CSA), total and BrdU+ myonuclei, Pax7+ nuclei, MyoD and myogenin protein and mRNA abundance and myosin heavy chain (MyHC) isoform composition. Mean fiber CSA, myonuclei/myofiber and Pax7+ nuclei/myofiber ratios were reduced in DEX compared to those in CON and PF muscles; CSA/myonucleus, $\mathrm{BrdU}+$ /total myonuclei and BrdU+ myonuclei/Pax7+ nuclei were similar among groups. Myogenin abundance was reduced and MyHC-slow was increased in DEX fetuses. The data are consistent with GLC inhibition of muscle progenitor cell proliferation limiting satellite cell and myonuclear accretion. The response of PF-fed compared to CON muscles indicated that decreased food consumption by DEX dams contributed to the smaller myofiber CSA but did not affect Pax7+ nuclear accretion. Thus, the effect on satellite cell reserve and myonuclear number also contributes to the blunting of fetal muscle growth by GLC.
\end{abstract}

Journal of Endocrinology (2017) 232, 561-572

\section{Introduction}

Growth restriction is a frequent and significant problem in the neonatal population and our understanding of its causes, management and long-term consequences are still limited. Low birth weight has been associated with abnormalities in adult body composition, including altered fat distribution and reduced muscle mass and strength (Yliharsila et al. 2007, Kulkarni et al. 2014). Additionally, historical cohort studies have shown positive 
correlations between birth weight and muscle mass and strength throughout life (Phillips 1995, Hediger et al. 1998, Kahn et al. 2000, Gale et al. 2001, Singhal et al. 2003, Sayer et al. 2004), suggesting that a reduced muscle mass may be programmed permanently by influences during intrauterine life that result in low birth weight. The two major environmental factors proposed to influence fetal programming are malnutrition and stress. In both these circumstances, precocious exposure of the fetus to inappropriately high levels of endogenous GLC is thought to occur (Langley-Evans et al. 1996, Lesage et al. 2001, Rehan et al. 2014). The potential of GLC to program permanent changes in physiologic functions also carries clinical significance because considerable numbers of premature neonates are subjected to antenatal or postnatal GLC treatment (Roberts \& Dalziel 2006, Seri 2006, Doyle et al. 2014).

The contribution of inappropriate fetal GLC exposure in the etiology of various adult morbidities such as hypertension, type 2 diabetes and obesity has been investigated experimentally in animal models where low birth weight has been a consistent outcome (Seckl 2004). However, few studies have assessed the impact of GLC exposure on fetal skeletal muscle growth and maturation. Previously, we demonstrated in a rat model that fetal exposure to GLCs reduced fetal growth and skeletal muscle mass (Gokulakrishnan et al. 2012). The reduction in skeletal muscle protein mass in the term fetus was due to the additive effects of GLC exposure and a modest global reduction in maternal food intake secondary to the GLC treatment and could be attributed to a reduction in muscle protein synthesis.

Skeletal muscle growth during the last third of gestation in rodents entails the formation of new secondary fibers within the existing muscle anlagen and the hypertrophy of both existing and secondary fibers (Condon et al. 1990). Both processes are subject to the regulated division, differentiation and fusion of secondary myoblasts and satellite cells. Satellite cells are muscle stem cells that can self-renew and are responsible for the addition of myonuclei to existent myofibers. Thus, if GLC alter these processes, the number of myofibers and/or their hypertrophy will be influenced. To the best of our knowledge, the effects of precocious in utero GLC exposure and the concurrent effects on maternal food intake on fetal fiber formation, myonuclear accretion and the satellite cell population have not been reported. The primary objective of the present experiment, therefore, was to determine the extent to which altered proliferation of muscle progenitor cells and myonuclear accretion contribute to the reduced skeletal muscle fiber hypertrophy of rat fetuses precociously exposed to high GLC levels during the latter half of gestation. Secondarily, because muscle maturation entails profound changes in the isoform composition of muscle contractile proteins which, together with the changes in myofiber mass, determine muscle function, we also characterized the relative expression levels of myosin heavy chain (MyHC) isoforms in the hind limb muscles and the diaphragm.

\section{Materials and methods}

\section{Animals and study design}

Timed pregnant female rats (Hsd:Sprague Dawley; Harlan Laboratories, Houston, TX, USA) were obtained on ED10 and housed individually in wire-bottom cages in a climate-controlled room at $23^{\circ} \mathrm{C}$ and a 12 -h light/darkness cycle. Body weight, food and water intake were measured daily from ED10 to ED22. The study was approved by the Animal Care and Use Committee of Baylor College of Medicine and conducted in accordance with the National Research Council's Guide for the Care and Use of Laboratory Animals and ARRIVE guidelines. More extensive details of the experiment have been published previously (Gokulakrishnan et al. 2012).

Dams were assigned to one of the 3 groups on ED12: control $(\mathrm{CON})$, dexamethasone (DEX)-treated and pairfed (PF) ( $n=7$ dams/treatment). Each DEX dam was paired to a weight-matched PF and CON dam. Dexamethasone (dexamethasone 21-acetate, Sigma-Aldrich) was dissolved in the drinking water at $1 \mathrm{mg} / \mathrm{L}$ and provided ad libitum from ED13. From the measurements of water intake, the average daily dose of dexamethasone acetate ingested was $\quad 84.6 \pm 4.1 \mu \mathrm{g} /(\mathrm{kg} /$ day $) \quad(194 \pm 9 \mathrm{nmol} /(\mathrm{kg} /$ day $))$. A control diet (Fiorotto et al. 2014) (Research Diets, New Brunswick, NJ, USA) was available ad libitum to DEX and CON dams. Beginning on ED14, the food intake of each DEX dam during the previous day was measured, and the weight-matched PF dam was provided the same amount in two aliquots on a body weight basis. Food intake was measured from the daily change in weight of the food jar minus spillage.

To quantify myonuclear accretion in vivo, three i.p. injections of 5-bromo-2'-deoxyuridine (BrdU; SigmaAldrich) in $0.9 \%$ sterile saline $(25 \mathrm{mgBrdU} / \mathrm{kg}$ body weight), were administered $12 \mathrm{~h}$ apart beginning $36 \mathrm{~h}$ before delivery.

Published by Bioscientifica Ltd. 
For delivery, each dam was anesthetized with isoflurane, the uterus was exposed and each fetus was rapidly dissected, weighed and placed in ice. Average fetal weight for the litter was calculated. For molecular analyses, the lower hind limb muscles and diaphragm from three fetuses that on average were of similar weight to the average weight for the litter were dissected and frozen in liquid nitrogen. The quadriceps from another three fetuses of similar weight to the litter mean were dissected quantitatively, weighed, mounted on a cork using gum tragacanth and frozen in liquid nitrogencooled isopentane. Samples were stored at $-80^{\circ} \mathrm{C}$ until analysis.

\section{Western blot assays}

Hind limb muscle extracts were prepared, and their protein concentrations were quantified (Fiorotto et al. 2014). For quantification of myogenin and MyoD, $25 \mu \mathrm{g}$ of protein extract were electrophoresed on 10\% SDS-polyacrylamide gels and transferred to polyvinylidene fluoride membranes. Membranes were blocked with 5\% (w/v) fat-free dry milk in $0.05 \mathrm{M}$ Tris-buffered saline/0.05\% (v/v) Tween 20 (TBS-T, pH 7.6) and subsequently incubated overnight at $4^{\circ} \mathrm{C}$ with primary antibodies to myogenin (clone F5D; Developmental Studies Hybridoma Bank, University of Iowa, Iowa City, USA), MyoD (clone 5.8A, BD Bioscience, San Jose, CA, USA) and $\alpha$-tubulin (loading control; $11 \mathrm{H} 10$; Cell Signaling). After rinsing in TBS-T, immunoblots were incubated with horseradish peroxidase (HRP)-conjugated secondary antibodies (goat anti-mouse IgG (H+L)-HRP conjugate (Bio-Rad, 170-6516) for myogenin and MyoD; goat anti-rabbit IgG (H+L)-HRP conjugate (Bio-Rad, 170$6515)$ for $\alpha$-tubulin) and visualized with ECL Plus (GE Lifesciences, Pittsburgh, PA, USA). Chemifluorescence was quantified using a STORM 860 Blot Imaging system (GE Lifesciences) and ImageQuant TL analysis software.

\section{Polyacrylamide gel electrophoresis of skeletal muscle MyHC isoforms}

Preparation of muscle protein extracts, gel preparation and electrophoresis were carried out as described by Smith and coworkers (Smith et al. 2014). Briefly, muscles were homogenized in low salt buffer (10mM Hepes, $1.5 \mathrm{mM} \mathrm{MgCl}, 10 \mathrm{mM} \mathrm{KCl}, 0.5 \%$ (v/v) NP40 and protease inhibitors (Complete Cocktail, Roche), $\mathrm{pH}$ 7.9) and added to an $8 \mathrm{M}$ urea/2M thiourea loading buffer. Another aliquot of homogenate was solubilized in $0.1 \mathrm{M} \mathrm{NaOH}$ and protein concentration was measured using the BCA reagent (Thermo Fisher) (Smith et al. 1985). Proteins were resolved on SDS-PAGE gels comprising a 4\% stacking gel (50:1 acrylamide:bis) containing 30\% (v/v) glycerol and

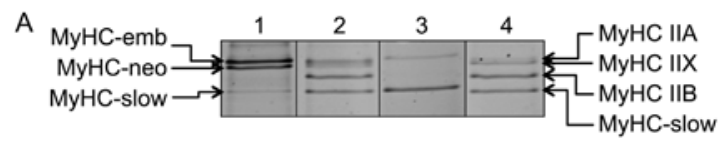

B

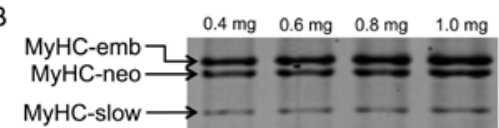

C
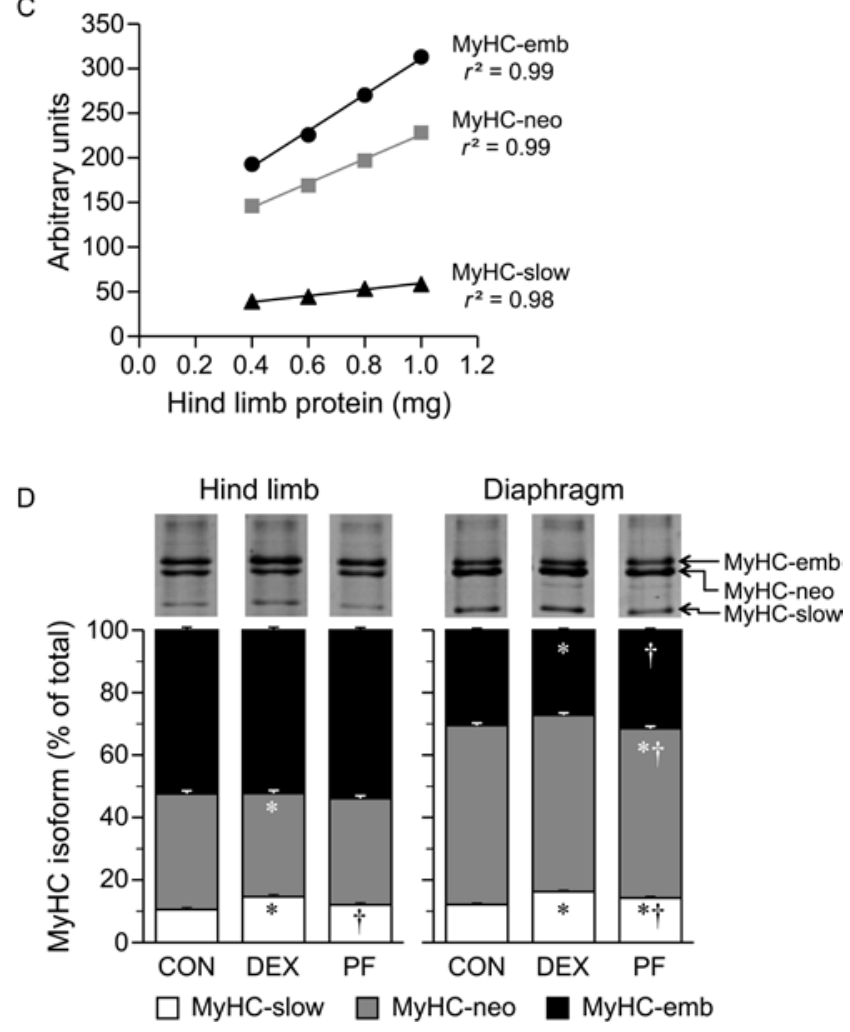

Figure 1

(A) SDS-PAGE gels stained with Sypro Ruby depicting myosin heavy chain (MyHC) isoforms in fetal hind limb muscles $(0.75 \mathrm{mg}$ protein; lane 1$)$; co-migration of adult soleus, adult gastrocnemius and fetal hind limb muscles (0.1, 0.05 and $0.05 \mathrm{mg}$ protein, respectively; lane 2$)$; adult soleus (0.1 mg protein; lane 3$)$; and adult soleus and adult gastrocnemius ( 0.05 and $0.05 \mathrm{mg}$ protein, respectively; lane 4); emb, embryonic; neo, neonatal. Please note that to facilitate comparisons, the gel image has been spliced for publication. (B) Representative example of gel showing bands corresponding to $\mathrm{MyHC}$ isoforms in a sample of hind limb muscle loaded in successively increasing doses $(0.4 \mathrm{mg}, 0.6 \mathrm{mg}, 0.8 \mathrm{mg}$ and $1 \mathrm{mg}$ protein). (C) Area of MyHC isoform bands plotted against total protein loaded. (D) Representative gels and relative amounts of MyHC-slow (white), MyHC-neo (grey), and MyHC-emb (black) in hind limb and diaphragm muscle from ED22 fetuses from control (CON), dexamethasone (DEX) and pair-fed (PF) dams. Values are means \pm S.E.M.; $n=6-7$ per group; $P<0.05$ : *DEX or PF vs CON; +PF vs DEX.
๑ 2017 Society for Endocrinology Printed in Great Britain 
an $8 \%$ separating gel (50:1 acrylamide:bis) containing $35 \%(\mathrm{v} / \mathrm{v})$ glycerol. Each muscle sample was loaded in 4 different amounts from 0.2 to $1 \mu \mathrm{g}$ protein in consecutive lanes and run for $48 \mathrm{~h}$ at $80 \mathrm{~V}$ (constant voltage) at $4^{\circ} \mathrm{C}$ (Fig. 1B). To identify MyHC bands, we analyzed adult muscles of known MyHC isoform composition (LaFramboise et al. 1990) and also co-electrophoresed these with fetal muscles (Fig. 1A). Then, on each pair of gels run concurrently, we loaded a 'reference' sample comprising adult soleus and fetal hind limb muscle extracts (Fig. 1A and B). Gels were stained in situ with Sypro Ruby (Life Technologies, Thermo Fisher) according to the manufacturer's recommendations. Stained gels were scanned, and band area was quantified using the STORM 860 imaging system and software. For each MyHC isoform, the area was plotted against the amount of protein loaded and from the slope of the regression line, the area/ $\mu \mathrm{g}$ protein for each isoform was determined (Fig. 1C). For each muscle, total MyHC area/ $\mu \mathrm{g}$ of protein was calculated, and individual isoforms were expressed as a percent of total MyHC. This procedure was necessary because preliminary analyses showed that MyHC isoforms differ in their staining intensity and the y-intercept of a dose-response curve varied, reflecting differences in background staining in different regions of the gel.

\section{Immunohistochemistry}

The quadriceps muscle was cryosectioned $(8 \mu \mathrm{m})$ and stained for dystrophin to visualize the sarcolemma and total and BrdU-labeled nuclei as described previously (Kao et al. 2016). A second slide was stained for Pax7, laminin and nuclei. Sections were fixed in $2 \%$ paraformaldehyde, permeabilized with $100 \%$ methanol at $-20^{\circ} \mathrm{C}$, followed by antigen retrieval $\left(0.01 \mathrm{M}\right.$ citric acid, $\mathrm{pH}$ 6) at $85^{\circ} \mathrm{C}$ for $20 \mathrm{~min}$. Sections were blocked in $5 \%(\mathrm{v} / \mathrm{v})$ normal goat serum, incubated overnight at $4^{\circ} \mathrm{C}$ with primary antibody to Pax7 (diluted to $8 \mu \mathrm{g} / \mathrm{mL}$; DSHB) and laminin (L9393; Sigma-Aldrich), followed by Alexa Fluor 488-conjugated goat antirabbit IgG (Invitrogen, Thermo Fisher) and biotinconjugated goat anti-mouse (Fcy subclass 1) IgG (Jackson ImmunoResearch) for $45 \mathrm{~min}$ at room temperature, and subsequently by streptavidin-conjugated Alexa Fluor 647 (Invitrogen) for $30 \mathrm{~min}$. Nuclei were stained with Sytox Orange (Invitrogen) and mounted as described previously. Sections where the primary antibody was omitted served as negative controls.

\section{Morphometry}

Images were captured by confocal microscopy (Olympus, FV300 Laser Scanning Confocal Microscope). Image analysis software (ImagePro Plus 6.2; Media Cybernetics, Silver Spring, MD, USA) was used to determine CSA outlined by the dystrophin-stained sarcolemma (Fig. 2A and Supplementary Fig. 1, see section on supplementary data given at the end of this article). Nuclei within the sarcolemma were classified as myonuclei and those that stained positive for BrdU were determined; at least 100 fibers were analyzed per fetus. Pax7+ nuclei were identified and their distribution between the interstitial space and beneath the basal lamina (the traditional satellite cell niche) was quantified (Fig. 3A and Supplementary Fig. 2); on average, 300 fibers per fetus were quantified. A proxy for myonuclear domain size was calculated by dividing
A

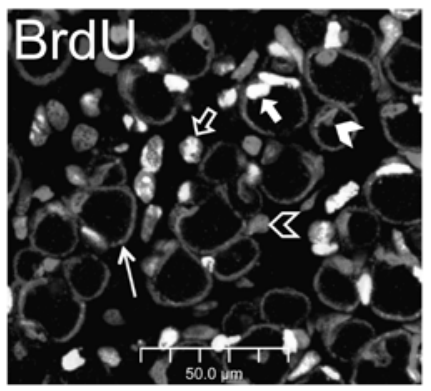

B

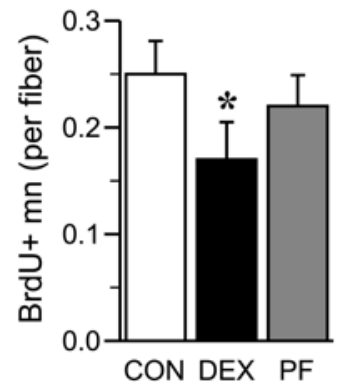

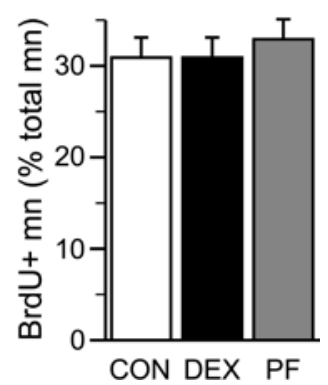

Figure 2

(A) Representative image of quadriceps muscle in cross-section stained for dystrophin, BrdU, and nuclei. Outlines of myofibers are identified by dystrophin staining of the sarcolemma (thin arrow). Within the confines of myofibers are myonuclei (grey spots; solid arrowhead) whereas those outside the confines of the myofibers are interstitial nuclei (grey spots; empty arrowhead); BrdU+ myonuclei (white spots; solid arrow) and interstitial nuclei (white spots; empty arrow) are also identified. (B) (Left panel) BrdU+ myonuclei (within the myofiber) per fiber in quadriceps muscle from CON (white bar), DEX (black bar), and PF (grey bar) fetuses; (right panel) BrdU+ myonuclei as a percent of total myonuclei. Values are means \pm s.E.M.; $n=6-7$ per group, $* P<0.05$, DEX vs CON and PF. 
A

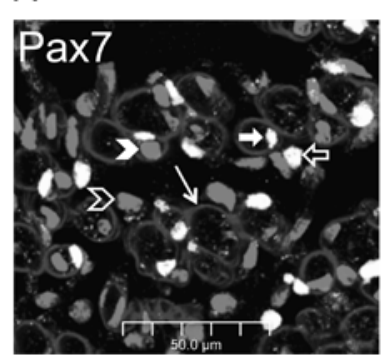

B

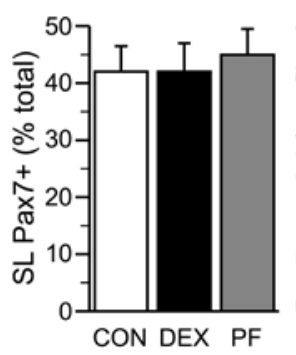

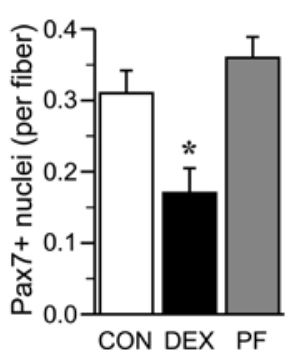

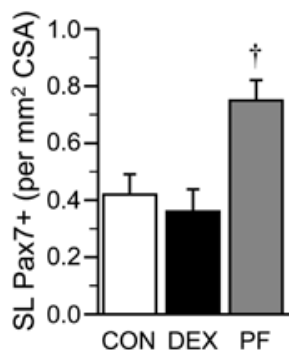

Figure 3

(A) Representative image of quadriceps muscle in cross-section stained for laminin, Pax7, and nuclei. Outlines of myofibers are identified by laminin staining of the basal lamina (thin arrow). Within the confines of myofibers are Pax7+ nuclei representing satellite cells (white spots; solid arrow) and in the interstitial space, representing nuclei of Pax7+ myogenic progenitor cells that have not yet reached the ultimate destination in the sublaminar space (white spots; empty arrow). Myonuclei (grey spots; solid arrowhead) and interstitial nuclei (grey spots; empty arrowhead) are also identified. (B) (Left panel) sublaminal (SL) Pax7+ nuclei (satellite cells) as a percent of total Pax7+ nuclei in quadriceps muscle from CON (white bar), DEX (black bar), and PF (grey bar) fetuses; (center panel) total Pax7+ nuclei per fiber (determined per field); (right panel) sublaminal (SL) Pax7+ nuclei (satellite cells) per cross-sectional area of fiber. Values are means \pm s.E.M.; ${ }^{\star} P<0.05, \mathrm{DEX}$ vs CON and $P F ;{ }^{\dagger} P<0.01$ PF vs CON and DEX; $n=6-7$ per group.

the mean fiber CSA by the number of myonuclei/fiber cross-section profile.

\section{mRNA quantification by quantitative reverse- transcriptase (RT) PCR}

Total RNA was extracted from hind limb muscle with TRIzol reagent (Thermo Fisher, Life Technologies) following the manufacturer's instructions. Quantification and RNA quality were verified via NanoDrop (ND-1000, NanoDrop Technologies, Thermo Fisher). cDNA was generated by RT-PCR using $1 \mu \mathrm{g}$ total RNA and qScript reagents (Quanta Biosciences, Beverly, MA, USA). Relative mRNA expression of Myod1 (forward primer (F): GCGCTCCAACTGCTCTGA; reverse primer (R): CTCTTCCCTGGTCTGGGCT), myogenin (F: GCCATCCAGTACATTGAGCG; R: GGGAGTTGCATTCACTGGGTA) and p-actin (F: CTAAGGCCAACCGTGAAAAGA; R: GGTACGACCAGAGGCATACA) was observed after verifying primer efficiency using quantitative PCR on a CFX96 qPCR system (Bio-Rad Laboratories) using SsoAdvanced SYBR green Supermix reagents (Bio-Rad). Data were expressed as $2-\Delta \Delta C$ t $u$ sing $\beta$-actin as reference gene $(\Delta 1)$ relative to CON values $(\Delta 2)$.

\section{Data analysis and statistics}

Values are presented as least square means \pm S.E.M. Because individual fetuses within a litter are not statistically independent, the number of replicates identified is the number of litters within each treatment group, and for each replicate, values from pups within a litter were averaged. Data were subjected to ANOVA using the general linear model (Minitab Statistical Software; Release 13.31,
State College, PA, USA). When a treatment effect was identified $(P<0.05$; allowing for multiple comparisons), post hoc pairwise comparisons among treatment groups was performed using Tukey's test. For outcomes that were assessed in both hind limb and diaphragm muscles, data were analyzed together, with treatment and muscle as main effects; when interactions between main effects were significant, data were analyzed separately.

\section{Results}

Data for the effects of the treatments on overall growth and muscle protein metabolism have been reported previously (Gokulakrishnan et al. 2012). To facilitate the assessment of the present data in context of the overall effects on fetal growth, the average body weights and muscle protein masses (muscle weight $\times$ protein concentration) are summarized here. At ED22, the average body weights of CON, DEX and PF fetuses were 5.1, 2.9 and $4.7 \mathrm{~g}$ (pooled SE, $0.2 \mathrm{~g}$ ), respectively (DEX vs $\mathrm{CON}$ and $\mathrm{PF}, P<0.01$; $\mathrm{CON}$ vs PF pups, not significant). The quadriceps protein mass (Table 1) in DEX offspring was 56\% $(P<0.01)$ of the CON group and $77 \%(P=0.05)$ of the PF group. Unlike body weight, quadriceps protein mass differed significantly between PF and CON groups (PF was $80 \%$ of $\mathrm{CON} ; P<0.01)$. To ascertain the exposure of DEX pups to GLC, and determine if the reduction in food intake and/or the BrdU injections generated sufficient stress to raise endogenous GLC levels, expression of the GLC-inducible gene, tyrosine aminotransferase (TAT) was determined in fetal liver from the same cohort by quantitative RT-PCR (Gokulakrishnan et al. 2012).

Published by Bioscientifica Ltd 
Table 1 Average protein mass, fiber cross-sectional area and myonuclear numbers of quadriceps muscles from ED22 fetuses of dams fed ad libitum on a control diet without (CON) or with dexamethasone treatment from ED13 to ED22 (DEX) or pair-fed (PF) to the DEX dams.

\begin{tabular}{|c|c|c|c|c|c|}
\hline & CON & DEX & PF & PSE & $\boldsymbol{P}$ \\
\hline $\begin{array}{l}\text { eps protein } \\
\text { ng) }\end{array}$ & $0.53^{a}$ & $0.30^{\mathrm{b}}$ & $0.42^{c}$ & 0.04 & $<c$ \\
\hline ber CSA $\left(\mu \mathrm{m}^{2}\right)$ & 29 & $203^{b}$ & $246 c *$ & 3 & 0.001 \\
\hline Myonuclei/myofiber & $0.79^{a}$ & $0.55^{b}$ & $0.67 \mathrm{ab}$ & 0.13 & 0.014 \\
\hline $\mathrm{CSA} /$ myonucleus $\left(\mu \mathrm{m}^{2}\right)$ & 384 & 377 & 372 & 72 & NS \\
\hline
\end{tabular}

Values are expressed as least square means, $n=7$ litters per group. Values in the same row with different superscripts are significantly different, $P<0.05$; ${ }^{*} P=0.085$ vs DEX group.

CSA, cross-sectional area; NS, not significant; PSE, pooled standard error.

Fetal liver TAT mRNA abundance was increased only in the DEX group $(P<0.001)$ and not different between the CON and PF groups suggesting no untoward GLC activity in these groups.

\section{Myofiber cross-sectional area}

There was a significant treatment effect on the mean fiber CSA $(P<0.001)$ that paralleled the differences in muscle protein masses (Table 1): both DEX and PF were significantly smaller than CON, and there was a tendency for DEX to be smaller than PF $(P=0.085)$. There was a left shift in the myofiber CSA distribution in DEX and

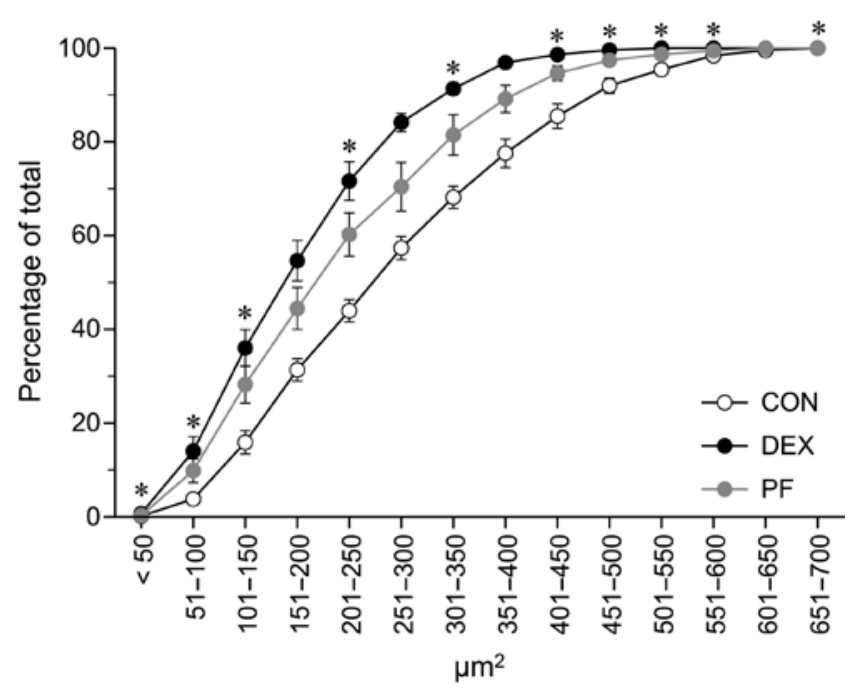

Figure 4

Cumulative percentage distribution of myofiber cross sectional areas (CSA) for the quadriceps muscle of ED22 fetuses from control (CON; white dots), dexamethasone (DEX; black dots) and pair fed (PF; grey dots). Values are means \pm S.E.M.; $x$-axis represents CSA bin sizes; $* P<0.05$, all treatments, $n=6-7$ per group.
PF relative to CON (Fig. 4) with the DEX and PF groups demonstrating approximately 30\% and 15\% reductions, respectively, across all fiber sizes.

\section{Myonuclear number}

There were fewer myonuclei per myofiber $(P<0.05)$ in the DEX group compared to those in CON (Table 1). The value for the PF group was intermediate and not different from either CON or DEX. The differences in myonuclei/ fiber were proportional to the differences in CSA and consequently myonuclear domain size (CSA/myonucleus; Table 1) was similar across all groups.

The number of BrdU+ myonuclei provides a measure of the proliferation and differentiation of satellite cells into myonuclei. Although there were significantly fewer BrdU+ myonuclei per fiber in the DEX group, the proportion of myonuclei that were BrdU+ was similar among groups (Fig. 2B). For the PF group, the number of BrdU+ myonuclei per fiber was intermediate to the CON and DEX values.

\section{Muscle progenitor cells}

Pax7+ nuclei were divided into 2 populations (Fig. 3A and Supplementary Fig. 1); approximately 40-45\% was located beneath the basal lamina in the classic satellite cell (referred to as such) location and the remainder was in the interstitial space. There was no treatment effect on the distribution of Pax7+ nuclei between the two sites (Fig. 3B). Relative to the number of myofibers within a field, both total Pax7+ nuclei and the satellite cell fraction were lower in the DEX group than those in either CON $(P<0.01)$ or PF groups $(P<0.001$; Fig. $3 \mathrm{~B})$; there was no difference between CON and PF. In the DEX group, the reduction in satellite cells was proportional to the reduction in CSA, but in the PF group, only the CSA was reduced so that satellite cells/CSA were higher $(P<0.01)$ than those in CON and DEX (Fig. 3B). The number of BrdU+ myonuclei per satellite cell was similar for all groups $(1.68 \pm 0.16)$.

\section{MyoD and myogenin}

There was no difference in MyoD abundance among groups for either hind limb or diaphragm muscles (Fig. 5A). In both muscles, DEX treatment reduced myogenin abundance by $27 \%(P<0.05)$ compared to that in $\mathrm{CON}$ and $\mathrm{PF}$ groups with no difference between $\mathrm{CON}$ and PF (Fig. 5B). Hind limb muscle $\beta$-actin mRNA expression did

Published by Bioscientifica Ltd. 
A
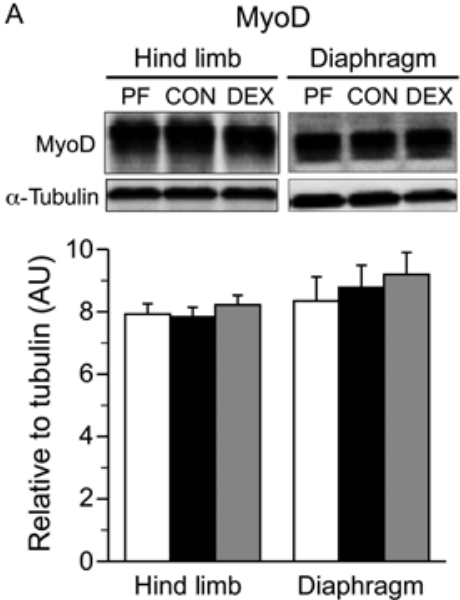

B
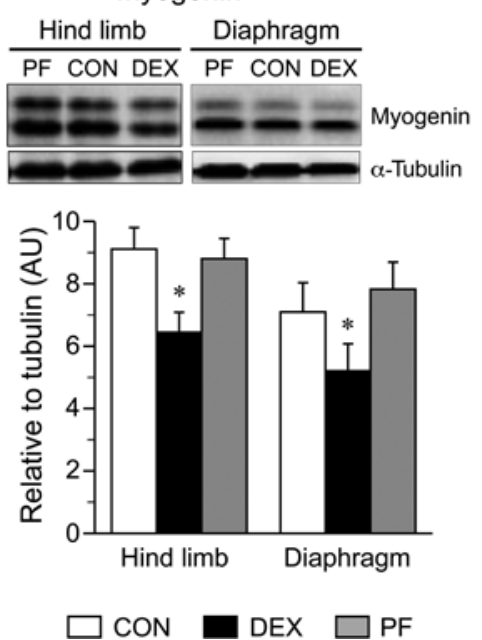

C

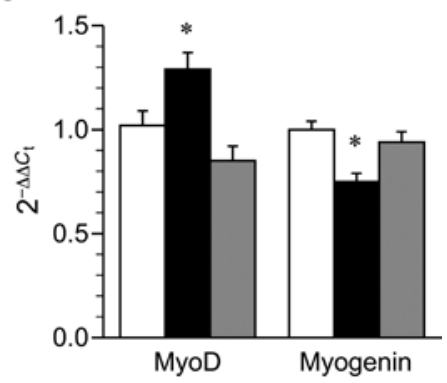

\section{Figure 5}

(A) Representative Western blots and quantitative values for MyoD and $\alpha$-tubulin (loading control) of hind limb and diaphragm muscles of ED22 fetuses from CON (white bar), DEX (black bar), PF (grey bar) dams. (B) Representative Western blots and quantitative values for myogenin and $\alpha$-tubulin (loading control) of hind limb and diaphragm muscles of ED22 fetuses from CON (white bar), DEX (black bar), PF (grey bar) dams. Values are means \pm s.E.M. expressed relative to $\alpha$-tubulin; $n=6-7$ per treatment; ${ }^{*} P<0.05$, DEX vs CON and PF. (C) Relative expression levels of $M y o D$ and $m y o g e n i n$ mRNA in hind limb muscles of ED22 fetuses from CON (white bar), DEX (black bar), PF (grey bar) dams. Values are means \pm S.E.M. expressed relative to $\beta$-actin (housekeeping mRNA $(\Delta 1)$ and average CON values $(\Delta 2) ;{ }^{*} P<0.05$, DEX vs CON and PF; $n=6-7$ per group.

not differ among groups $(19.25 \pm 0.67$ (s.D.) Ct; $P=0.31)$. MyoD mRNA expression was significantly greater in DEX hind limb muscles compared to that in either $\mathrm{CON}$ or PF, whereas myogenin mRNA was significantly lower (Fig. 5C). There were no differences between CON and PF.

\section{MyHC protein isoforms}

We identified three MyHC isoforms: embryonic (emb), neonatal (neo) and slow (Fig. 1A). In the hind limb muscles, approximately 50\% was MyHC-emb, and this proportion was similar among groups (Fig. 1D). MyHCslow was almost $50 \%$ higher in the DEX group than that in CON and was compensated for by reduced MyHC-neo. In the PF group, differences were minor compared to the CON group.

In the diaphragm, MyHC-neo comprised the largest proportion of MyHC and was similar in CON and DEX groups (Fig. 1D). There was a larger proportion of MyHCslow in the DEX muscle than that in CON $(P<0.001)$ and PF $(P=0.02)$ muscles, with a decrease in the proportion of MyHC-emb relative to both CON $(P<0.001)$ and PF $(P<0.001)$. Compared to CON, the PF diaphragm contained a slightly higher proportion of MyHC-slow $(P<0.02)$, but less MyHC-neo $(P<0.02)$, and no difference in MyHC-emb. This inverse change in MyHC-slow and -neo are more similar to the DEX response observed for the hind limb muscles.

\section{Discussion}

Skeletal muscle is necessary for vital functions such as breathing, feeding and locomotion. For newborns, the successful transition to extra-uterine life is critically dependent on the first two of these, and any compromise will result in numerous short- and long-term morbidities and incur high costs. Thus, it is critical that we understand the consequences incurred when an adverse intrauterine environment precludes normal development. As a consequence of maternal stress, malnutrition or when maternal medical conditions necessitate their administration, precocious exposure of the fetus to elevated GLC can occur.

The dose of dexamethasone and its route of administration we studied were based on published literature on the role of GLC in fetal programming (Hewitt et al. 2006, Mark et al. 2014). Based on the pharmacokinetics of DEX in pregnant rat dams (Samtani et al. 2004, 2006, Samtani \& Jusko 2005), its bioavailability (Spoorenberg et al. 2014), and assuming a constant intake over $24 \mathrm{~h}$, steady state levels of DEX of approximately $15 \mathrm{ng} / \mathrm{mL}$ would have been attained. Given that the biological activity of DEX is approximately 30 times that of the endogenous hormone (Axelrod 2001), these maternal DEX levels are equivalent to a plasma total corticosterone concentration of $450 \mathrm{ng} / \mathrm{mL}$. This concentration is approximately threefold higher than

Published by Bioscientifica Ltd. 
that in unstressed dams at term (Williams et al. 1999, Somm et al. 2012, Rehan et al. 2014) and similar to values in rat dams that have been food restricted by $50-70 \%$ for a significant part of gestation (Somm et al. 2012, Rehan et al. 2014). In the event of threatened preterm labor in humans, a cumulative dose of $\sim 400 \mu \mathrm{g} / \mathrm{kg}$ is administered over 2 days. In our study, the cumulative dose (assuming oral bioavailability to be $80 \%$ ) was $\sim 544 \mu \mathrm{g} / \mathrm{kg}$ over the course of 8 days. Thus, the chronicity and plasma level of DEX achieved in our study more closely models the GLC response to chronic maternal food restriction. We demonstrated that one outcome of DEX administration to pregnant rat dams was to adversely affect intrauterine fetal skeletal muscle growth and protein turnover (Gokulakrishnan et al. 2012). This was due to the additive effect of DEX and the associated reduction in food intake. In the present study, we demonstrate that DEX also adversely affects myogenic progenitor cell proliferation and that this is independent of maternal food intake. This response likely contributed to reducing fetal muscle growth and could incur a permanent reduction in muscle mass.

The transcription factor, Pax7 plays a central role in myogenesis. Hind limb muscles are derived from Pax3/7+ embryonic and fetal myoblasts that originate in the hypaxial dermomyotome (Murphy \& Kardon 2011). After delamination at approximately mid-gestation, myoblasts migrate into the interstitial spaces in the limb muscle anlagen where they activate the myogenic program and differentiate, initially forming primary myofibers and, subsequently, secondary myofibers. For technical reasons, we did not measure fiber number at ED22, but we deduced the effect of GLC exposure on fiber formation in a separate experiment in which GLC-exposed fetuses were cross-fostered and suckled from birth by CON dams and studied at 4 week of age. We found no effect of intrauterine GLC exposure on fiber number in the extensor digitorum longus muscle of the hind limb (Supplementary Table 1). Because a deficiency in fiber number incurred before birth is not recoverable (Wilson et al. 1988), these results suggest that DEX treatment did not affect fiber formation from primary and secondary myoblasts.

Accretion of myonuclei to support myofiber hypertrophy is a function of a third population of Pax7+ progenitor cells that originate in the somites and migrate into the muscle beds (Lepper \& Fan 2010). Here, they are enclosed by the basal lamina from ED14 to ED15 in the rat and by ED19, when the fibers are completely ensheathed (Chiu \& Sanes 1984), these cells occupy a sublaminal niche and are termed satellite cells. Our results demonstrate that by ED22, exposure to DEX from ED13 resulted in a $45 \%$ decrease in total Pax7+ cells. This decrease was equivalent for Pax7+ cells in the sublaminal and interstitial positions suggesting that, although fewer, their tempo of migration and fusion was not altered by DEX.

Fewer Pax7+ cells could occur as a result of reduced cell division, higher rates of differentiation and fusion relative to proliferation rates and/or increased cell death. The lower abundance of myogenin mRNA and protein in the absence of differences in MyoD protein in both hind limb muscles and diaphragm of DEX fetuses does not support the possibility that differentiation was accelerated. This conclusion is supported by in vitro studies in which both $\mathrm{C} 2 \mathrm{C} 12$ myoblasts and isolated primary satellite cells demonstrated reduced proliferative activity and differentiation when incubated with DEX even at relatively low concentrations (te Pas et al. 2000, Dong et al. 2013). Additionally, in vitro studies have shown post-translational regulation of myogenin by GLC through activation of the E3-ligase, MAFbx1/atrogin, that targets myogenin for degradation by the ubiquitinproteasome pathway (Jogo et al. 2009). This explanation may be pertinent because previously we demonstrated that expression of MAFbx1/atrogin was increased in fetal muscles exposed to GLC (Gokulakrishnan et al. 2012). Although MAFbx1/atrogin also interacts with MyoD to promote its degradation by the ubiquitin-proteasome system (Tintignac et al. 2005, Sun et al. 2008), we found no differences in total MyoD protein among groups. However, the higher mRNA expression suggests that DEX promoted MyoD transcription as has a been observed in proliferating and differentiating $\mathrm{C} 2 \mathrm{C} 12$ myoblasts (te Pas et al. 2000). Thus, GLC appear to increase the turnover of MyoD without necessarily altering its steady state total abundance.

Although an increase in the dexamethasone-induced cell death could have contributed to the reduction in Pax7+ cells, in vitro studies that used substantially higher DEX concentrations than those to which the fetuses were exposed, found no increase in muscle cell apoptosis (Singleton et al. 2000, te Pas et al. 2000). The induction of steroid-induced myopathies associated with enhanced cell death in vivo requires GLC doses that are at least 10to 20-fold higher than those used in this study (Lee et al. 2005). Thus, it seems unlikely that this mechanism contributed to the decrease in Pax7+ cells in DEX fetuses.

The presence of fewer satellite cells in the DEX fetuses likely contributed to the reduction in total and BrdU+ myonuclei per fiber. The ratio of BrdU+ myonuclei per satellite cell provides a measure of the proliferation

Published by Bioscientifica Ltd 
of the existent satellite cells. Because these values were similar across treatment groups, the result suggests that rates of satellite cell proliferation and differentiation into myonuclei during the labeling period were similar across treatment. However, in the context of fewer BrdU+ myonuclei per fiber and a proportional decrease in total myonuclei, one can surmise that the deficit in total Pax7+ progenitor cells in DEX fetuses was incurred before ED20. The physiological surge in endogenous fetal GLC between ED18 and ED21 may also have mitigated group differences over the period of BrdU administration (Ward \& Weisz 1984, Boudouresque et al. 1988, Williams et al. 1999, Samtani et al. 2006).

Myonuclear domain size (CSA/myonucleus) is considered to represent the limits of influence of a myonucleus on its surrounding cytoplasm in terms of transcriptional and translational capacity. Myonuclear domain size in skeletal muscle increases during maturational muscle growth to attain a size that largely remains constant throughout life for a given fiber type (Van der Meer et al. 2011). Despite the differences in mass, the average myonuclear domain size was similar across all groups. This result indicates that the smaller skeletal muscle mass in both PF and DEX groups was associated with proportionally fewer myonuclei and less myofiber cytoplasm and suggests a close inter-dependence of nuclear hyperplasia and myofiber hypertrophy. A comparison among groups in the fiber CSA distribution indicated a left shift across all fibers, suggesting that all fibers were affected proportionately. Taken together, these results are consistent with a blunting of satellite cell proliferation during myofiber formation, when the fetus is precociously exposed to GLC. This effects a reduction in the acquisition of myonuclei which in turn contributes to diminished skeletal muscle fiber hypertrophy.

The consequences of reduced maternal food intake during gestation on satellite numbers appear to depend on the degree of food restriction. Fewer satellite cells with no effect on fiber number were observed in the muscles of offspring from dams that were food restricted by $50 \%$ after the first week of gestation (Beermann 1983, Beermann et al. 1983, Woo et al. 2011). This degree of food restriction increases endogenous GLC levels in the mother and fetus and ultimately may be responsible for mediating the effects of severe maternal undernutrition on fetal satellite cells (Lesage et al. 2001, Rehan et al. 2014). However, in our study Pax7+ cells/myofiber for the PF group were similar to those of $\mathrm{CON}$ offspring, suggesting that milder maternal undernutrition $(\sim 13 \%$ less food intake than $\mathrm{CON}$ ) does not compromise the production of Pax7+ progenitor cells in fetal muscle. The absence of any differences in $M y o D$ or myogenin mRNA and protein further corroborate this conclusion. Thus, the increase in satellite cells/CSA in the PF group is likely due to reduced fiber protein accretion and the decreased CSA, rather than an increase in satellite cell number. Taken together, our data suggest that the effects of in utero GLC exposure on fetal myonuclear accretion are independent of the effects of mild maternal nutrient restriction. Moreover, our data indicate that in the fetus muscle protein anabolism is more sensitive to nutrient supply than muscle progenitor cell proliferation.

MyHC isoform expression in the developing skeletal muscle undergoes profound changes that depend on the origin of the fiber and developmental age (Condon et al. 1990). By comparing the expression of MyHC across groups, inferences can be made regarding the effects of GLC and undernutrition on this index of muscle maturation. In the rat, all newly differentiated primary fibers express slow and embryonic MyHC, whereas secondary fibers express embryonic and neonatal MyHC (Condon et al. 1990, Schiaffino \& Reggiani 1994). Toward the end of gestation, some primary fibers in future fast muscles (the majority of hind limb muscles in the rat) continue to express slow MyHC, whereas the majority undergo a developmental switch in which MyHC-slow is replaced by MyHC-neo. Postnatally, these primary fibers mature into fibers expressing fast MyHC isoforms. Although secondary fibers mostly mature into fast fibers, a small proportion, transition from embryonic to neonatal to slow MyHC. In adult muscle, pharmacological doses of GLC produce a fast-to-slow fiber-type transformation and selective atrophy of fast fibers (Polla et al. 1994, Seene \& Kaasik 2016). Hind limb muscles of DEX fetuses contained a relatively greater abundance of MyHCslow than CON muscles with proportionately lower MHC-neo and, importantly, no difference in MHCemb. Thus, we questioned whether this observation was indicative of fiber-type transformation and selective atrophy of secondary fibers (future fast fibers), as occurs in adult muscles, or an effect on maturation. Given the substantially lower dose of GLC we administered, and in the absence of selective effects on large (primary) or small (secondary) fiber CSA, we deduce that the differences in $\mathrm{MyHC}$ isoform expression represent an effect on muscle maturation. Specifically, a delay in primary fiber maturation would blunt the MHC-slow to -neo transition, as we observed. In the diaphragm, the higher proportion 
of MyHC-neo confirms that at term, this muscle is more mature than the hind limb muscles (d'Albis et al. 1989, Kelly et al. 1991, Agbulut et al. 2003). In the diaphragm of DEX fetuses, the relative decrease in MyHC-emb and increase in MHC-slow compared to CON, suggests an advancement of maturation and possibly an increase in the transformation of fibers to the slow fiber program. The functional consequences of these effects are uncertain: reduced maximal force production consistent with the effects on MyHC composition have been observed in newborn rats administered high doses of GLC (Trang et al. 1992), whereas functional effects after brief exposure to GLC in utero were evident only after recovery (Song et al. 2014). The results from the PF muscles indicate that the mild maternal food restriction contributed minimally to the maturation of muscles and may have served to blunt the effect of DEX in the diaphragm.

There are certain limitations of this study. Gender differences were not studied. Although in a recent report no sex differences in birth weight were observed after a DEX infusion of $100 \mu \mathrm{g} /(\mathrm{kg} / \mathrm{day})$ throughout gestation (Somm et al. 2012), there is growing evidence for both humans and animal models that following exposure to an adverse intrauterine environment, some outcomes can be sex-specific (Aiken \& Ozanne 2013, Cuffe et al. 2017). Fiber morphometry measurements were made on the quadriceps muscle, whereas the MyHC isoform distribution and myogenin and MyoD measurements were determined on hind limb muscle homogenates. At this age, however, muscle development proceeds in a relatively autonomous manner and the range of phenotype is primarily influenced by the location. Thus, it is not unreasonable to assume that the properties of the quadriceps are representative of other hind limb muscles. The histology of the diaphragm was not of sufficient quality to enable unequivocal localization of nuclei which, therefore, precluded quantification of the various nuclear populations. Additionally, only one time point was studied. The findings noted at ED22 reflect an accumulation of the treatment effects from earlier stages of development. Thus, we can only make inferences regarding events that occurred earlier.

\section{Conclusion, perspectives and significance}

Despite the previously mentioned shortcomings, the results unequivocally demonstrate that the precocious exposure in utero to modestly increased GLC levels produces an absolute decrease in Pax $7+$ progenitor cells that is independent of maternal nutritional status. This response compromises the satellite cell reserve and myonuclear number by birth. However, the smaller fiber CSA of fetuses from PF compared to that from CON dams indicates that the decrease in myofiber CSA in DEX muscles can be attributed in part to the decrease in the dams' food consumption. These findings are important because satellite cells are responsible for the postnatal increase in myonuclei. As stem cells, they proliferate to maintain their pool size and to expand myonuclear numbers in myofibers. The highest growth velocity of skeletal muscle occurs in the perinatal period once the myofibers are established and requires accelerated rates of myonuclear accretion to support the hypertrophy of fibers. Thus, it is critical that an optimal complement of satellite cells is present at birth to ensure appropriate postnatal skeletal muscle growth. Whether a compromised newborn can overcome a $\sim 45 \%$ deficit in satellite cells to restore muscle growth is uncertain. Incomplete recovery would have significant negative consequences, not only in the short term, but possible extending through the lifespan (Janssen et al. 2004, Kimyagarov et al. 2010). Follow-up studies, therefore, are crucial to establish if precocious intrauterine GLC exposure results in a permanent reduction in satellite cell number and skeletal muscle mass or if these can be recovered once GLC are withdrawn and adequate nutrition restored postnatally.

\section{Supplementary data}

This is linked to the online version of the paper at http://dx.doi.org/ 10.1530/JOE-16-0372.

\section{Declaration of interest}

The authors declare that there is no conflict of interest that could be perceived as prejudicing the impartiality of the research reported.

\section{Funding}

These studies were supported by grants from USDA CRIS 6250-51000-054 and NIH AR46308 to M L F and funds from the Department of Pediatrics, Baylor College of Medicine to G G.

\section{Author contribution statement}

Author contributions: G G and M L F conception and design of research; G G, X C, R F and M L F performed experiments; G G and M L F analyzed data; G G and M L F interpreted results of experiments; $G$ G prepared figures; G G and M L F drafted the manuscript; G G and M L F edited and revised manuscript; all authors approved the final version of the manuscript. 


\section{Acknowledgements}

The authors thank E O'Brian Smith for assistance with statistical analyses, Adam Gillum for graphics and Jerome Stubblefield for assistance with animal husbandry. The authors would also like to thank Dr Steve Welty (Section of Neonatology, Department of Pediatrics, Baylor College of Medicine) for his input. This work is a publication of the USDA, Agricultural Research Service Children's Nutrition Research Center, Department of Pediatrics, Baylor College of Medicine, Houston, TX, USA. The contents of this publication do not necessarily reflect the views or politics of the USDA, nor does the mention of trade names, commercial products or organizations imply endorsement by the U.S. government.

\section{References}

Agbulut O, Noirez P, Beaumont F \& Butler-Browne G 2003 Myosin heavy chain isoforms in postnatal muscle development of mice. Biology of the Cell 95 399-406. (doi:10.1016/S0248-4900(03)00087-X)

Aiken CE \& Ozanne SE 2013 Sex differences in developmental programming models. Reproduction 145 R1-R13. (doi:10.1530/REP11-0489)

Axelrod R 2001 Corticosteroid therapy. In Principles and Practice of Endocrinology and Metabolism, edn 3rd, pp 751-764. Ed KL Becker. Philadelphia, PA, USA: Lippincott Williams and Wilkins.

Beermann DH 1983 Effects of maternal dietary restriction during gestation and lactation, muscle, sex, and age on various indices of skeletal muscle growth in the rat. Journal of Animal Science $\mathbf{5 7}$ 328-337. (doi:10.2527/jas1983.572328x)

Beermann DH, Hood LF \& Liboff M 1983 Satellite cell and myonuclei populations in rat soleus and extensor digitorum longus muscles after maternal nutritional deprivation and realimentation. Journal of Animal Science 57 1618-1625. (doi:10.2527/jas1983.5761618x)

Boudouresque F, Guillaume V, Grino M, Strbak V, Chautard T, Conte-Devolx B \& Oliver C 1988 Maturation of the pituitaryadrenal function in rat fetuses. Neuroendocrinology 48 417-422. (doi:10.1159/000125043)

Chiu AY \& Sanes JR 1984 Development of basal lamina in synaptic and extrasynaptic portions of embryonic rat muscle. Developmental Biology 103 456-467. (doi:10.1016/0012-1606(84)90333-6)

Condon K, Silberstein L, Blau HM \& Thompson WJ 1990 Development of muscle fiber type in the prenatal rat hindlimb. Developmental Biology 138 256-274. (doi:10.1016/0012-1606(90)90196-P)

Cuffe JS, Turton EL, Akison LK, Bielefeldt-Ohmann H \& Moritz KM 2017 Prenatal corticosterone exposure programs sex-specific adrenal adaptations in mouse offspring. Journal of Endocrinology 232 37-48. (doi:10.1530/JOE-16-0417)

d'Albis A, Couteaux R, Janmot C \& Roulet A 1989 Specific programs of myosin expression in the postnatal development of rat muscles. European Journal of Biochemistry 183 583-590. (doi:10.1111/j.1432-1033.1989.tb21087.x)

Dong Y, Pan JS \& Zhang L 2013 Myostatin suppression of Akirin1 mediates glucocorticoid-induced satellite cell dysfunction. PLOS ONE 8 e58554. (doi:10.1371/journal.pone.0058554)

Doyle LW, Halliday HL, Ehrenkranz RA, Davis PG \& Sinclair JC 2014 An update on the impact of postnatal systemic corticosteroids on mortality and cerebral palsy in preterm infants: effect modification by risk of bronchopulmonary dysplasia. Journal of Pediatrics 165 1258-1260. (doi:10.1016/j.jpeds.2014.07.049)

Fiorotto ML, Davis TA, Sosa HA, Villegas-Montoya C, Estrada I \& Fleischmann R 2014 Ribosome abundance regulates the recovery of skeletal muscle protein mass upon recuperation from postnatal undernutrition in mice. Journal of Physiology 592 5269-5286. (doi:10.1113/jphysiol.2014.279067)

Gale CR, Martyn CN, Kellingray S, Eastell R \& Cooper C 2001 Intrauterine programming of adult body composition. Journal of
Clinical Endocrinology and Metabolism 86 267-272. (doi:10.1210/ jc.86.1.267)

Gokulakrishnan G, Estrada IJ, Sosa HA \& Fiorotto ML 2012 In utero glucocorticoid exposure reduces fetal skeletal muscle mass in rats independent of effects on maternal nutrition. American Journal of Physiology: Regulatory, Integrative and Comparative Physiology 302 R1143-R1152. (doi:10.1152/ajpregu.00466.2011)

Hediger ML, Overpeck MD, Kuczmarski RJ, McGlynn A, Maurer KR \& Davis WW 1998 Muscularity and fatness of infants and young children born small- or large-for-gestational-age. Pediatrics 102 E60. (doi:10.1542/peds.102.5.e60)

Hewitt DP, Mark PJ \& Waddell BJ 2006 Glucocorticoids prevent the normal increase in placental vascular endothelial growth factor expression and placental vascularity during late pregnancy in the rat. Endocrinology 147 5568-5574. (doi:10.1210/en.2006-0825)

Janssen I, Baumgartner RN, Ross R, Rosenberg IH \& Roubenoff R 2004 Skeletal muscle cutpoints associated with elevated physical disability risk in older men and women. American Journal of Epidemiology 159 413-421. (doi:10.1093/aje/kwh058)

Jogo M, Shiraishi S \& Tamura TA 2009 Identification of MAFbx as a myogenin-engaged F-box protein in SCF ubiquitin ligase. FEBS Letters 583 2715-2719. (doi:10.1016/j.febslet.2009.07.033)

Kahn HS, Narayan KM, Williamson DF \& Valdez R 2000 Relation of birth weight to lean and fat thigh tissue in young men. International Journal of Obesity and Related Metabolic Disorders 24 667-672. (doi:10.1038/ sj.ijo.0801211)

Kao M, Columbus DA, Suryawan A, Steinhoff-Wagner J, Hernandez-Garcia A, Nguyen HV, Fiorotto ML \& Davis TA 2016 Enteral beta-hydroxy-beta-methylbutyrate supplementation increases protein synthesis in skeletal muscle of neonatal pigs. American Journal of Physiology: Endocrinology and Metabolism 310 E1072-E1084. (doi:10.1152/ajpendo.00520.2015)

Kelly AM, Rosser BW, Hoffman R, Panettieri RA, Schiaffino S, Rubinstein NA \& Nemeth PM 1991 Metabolic and contractile protein expression in developing rat diaphragm muscle. Journal of Neuroscience 11 1231-1242.

Kimyagarov S, Klid R, Levenkrohn S, Fleissig Y, Kopel B, Arad M \& Adunsky A 2010 Body mass index (BMI), body composition and mortality of nursing home elderly residents. Archives of Gerontology and Geriatrics 51 227-230. (doi:10.1016/j.archger.2009.10.013)

Kulkarni B, Hills AP \& Byrne NM 2014 Nutritional influences over the life course on lean body mass of individuals in developing countries. Nutrition Reviews 72 190-204. (doi:10.1111/nure.12097)

LaFramboise WA, Daood MJ, Guthrie RD, Moretti P, Schiaffino S \& Ontell M 1990 Electrophoretic separation and immunological identification of type $2 \mathrm{X}$ myosin heavy chain in rat skeletal muscle. Biochimica et Biophysica Acta 1035 109-112. (doi:10.1016/03044165(90)90181-U)

Langley-Evans SC, Phillips GJ, Benediktsson R, Gardner DS, Edwards CR, Jackson AA \& Seckl JR 1996 Protein intake in pregnancy, placental glucocorticoid metabolism and the programming of hypertension in the rat. Placenta 17 169-172. (doi:10.1016/S0143-4004(96)80010-5)

Lee MC, Wee GR \& Kim JH 2005 Apoptosis of skeletal muscle on steroidinduced myopathy in rats. Journal of Nutrition 135 1806S-1808S.

Lepper C \& Fan CM 2010 Inducible lineage tracing of Pax7-descendant cells reveals embryonic origin of adult satellite cells. Genesis $\mathbf{4 8}$ 424-436. (doi:10.1002/dvg.20630)

Lesage J, Blondeau B, Grino M, Breant B \& Dupouy JP 2001 Maternal undernutrition during late gestation induces fetal overexposure to glucocorticoids and intrauterine growth retardation, and disturbs the hypothalamo-pituitary adrenal axis in the newborn rat. Endocrinology 142 1692-1702. (doi:10.1210/en.142.5.1692)

Mark PJ, Wyrwoll CS, Zulkafli IS, Mori TA \& Waddell BJ 2014 Rescue of glucocorticoid-programmed adipocyte inflammation by omega-3 fatty acid supplementation in the rat. Reproductive Biology and Endocrinology 12 39. (doi:10.1186/1477-7827-12-39) 
Murphy M \& Kardon G 2011 Origin of vertebrate limb muscle: the role of progenitor and myoblast populations. Current Topics in Developmental Biology 96 1-32. (doi:10.1016/b978-0-12-385940-2.00001-2)

Phillips DI 1995 Relation of fetal growth to adult muscle mass and glucose tolerance. Diabetic Medicine 12 686-690. (doi:10.1111/j.1464-5491.1995.tb00570.x)

Polla B, Bottinelli R, Sandoli D, Sardi C \& Reggiani C 1994 Cortisoneinduced changes in myosin heavy chain distribution in respiratory and hindlimb muscles. Acta Physiologica Scandinavica 151 353-361. (doi:10.1111/j.1748-1716.1994.tb09754.x)

Rehan VK, Li Y, Corral J, Saraswat A, Husain S, Dhar A, Sakura R, Khorram O \& Torday JS 2014 Metyrapone blocks maternal food restriction-induced changes in female rat offspring lung development. Reproductive Sciences 21 517-525. (doi:10.1177/ 1933719113503404)

Roberts D \& Dalziel S 2006 Antenatal corticosteroids for accelerating fetal lung maturation for women at risk of preterm birth. Cochrane Database of Systematic Reviews 19 CD004454. (doi:10.1002/14651858. CD004454.pub2)

Samtani MN \& Jusko WJ 2005 Comparison of dexamethasone pharmacokinetics in female rats after intravenous and intramuscular administration. Biopharmaceutics and Drug Disposition 26 85-91. (doi:10.1002/bdd.435)

Samtani MN, Schwab M, Nathanielsz PW \& Jusko WJ 2004 Area/moment and compartmental modeling of pharmacokinetics during pregnancy: applications to maternal/fetal exposures to corticosteroids in sheep and rats. Pharmaceutical Research 21 2279-2292. (doi:10.1007/s11095004-7681-7)

Samtani MN, Pyszczynski NA, DuBois DC, Almon RR \& Jusko WJ 2006 Modeling glucocorticoid-mediated fetal lung maturation: I. Temporal patterns of corticosteroids in rat pregnancy. Journal of Pharmacology and Experimental Therapeutics 317 117-126. (doi:10.1124/jpet.105.095851)

Sayer AA, Syddall HE, Dennison EM, Gilbody HJ, Duggleby SL, Cooper C, Barker DJ \& Phillips DI 2004 Birth weight, weight at $1 \mathrm{y}$ of age, and body composition in older men: findings from the Hertfordshire Cohort Study. American Journal of Clinical Nutrition 80 199-203.

Schiaffino S \& Reggiani C 1994 Myosin isoforms in mammalian skeletal muscle. Journal of Applied Physiology 77 493-501.

Seckl JR 2004 Prenatal glucocorticoids and long-term programming. European Journal of Endocrinology 151 (Supplement 3) U49-U62. (doi:10.1530/eje.0.151U049)

Seene T \& Kaasik P 2016 Role of myofibrillar protein catabolism in development of glucocorticoid myopathy: aging and functional activity aspects. Metabolites 6 E15. (doi:10.3390/metabo6020015)

Seri I 2006 Hydrocortisone and vasopressor-resistant shock in preterm neonates. Pediatrics 117 516-518. (doi:10.1542/peds.2005-2057)

Singhal A, Wells J, Cole TJ, Fewtrell M \& Lucas A 2003 Programming of lean body mass: a link between birth weight, obesity, and cardiovascular disease? American Journal of Clinical Nutrition 77 726-730.

Singleton JR, Baker BL \& Thorburn A 2000 Dexamethasone inhibits insulin-like growth factor signaling and potentiates myoblast apoptosis. Endocrinology 141 2945-2950. (doi:10.1210/endo.141.8.7621)

Smith PK, Krohn RI, Hermanson GT, Mallia AK, Gartner FH, Provenzano MD, Fujimoto EK, Goeke NM, Olson BJ \& Klenk DC 1985 Measurement of protein using bicinchoninic acid. Analytical Biochemistry 150 76-85. (doi:10.1016/00032697(85)90442-7)
Smith HK, Matthews KG, Oldham JM, Jeanplong F, Falconer SJ, Bass JJ, Senna-Salerno M, Bracegirdle JW \& McMahon CD 2014 Translational signalling, atrogenic and myogenic gene expression during unloading and reloading of skeletal muscle in myostatin-deficient mice. PLoS ONE 9 e94356. (doi:10.1371/journal.pone.0094356)

Somm E, Vauthay DM, Guerardel A, Toulotte A, Cettour-Rose P, Klee P, Meda P, Aubert ML, Huppi PS \& Schwitzgebel VM 2012 Early metabolic defects in dexamethasone-exposed and undernourished intrauterine growth restricted rats. PLOS ONE 7 e50131. (doi:10.1371/ journal.pone.0050131)

Song Y, Demmer DL, Pinniger GJ, Lavin T, MacMillan MV, Pillow JJ \& Bakker AJ 2014 Effect of maternal steroid on developing diaphragm integrity. PLOS ONE 9 e93224. (doi:10.1371/journal. pone.0093224)

Spoorenberg SM, Deneer VH, Grutters JC, Pulles AE, Voorn GP, Rijkers GT, Bos WJ \& van de Garde EM 2014 Pharmacokinetics of oral vs. intravenous dexamethasone in patients hospitalized with community-acquired pneumonia. British Journal of Clinical Pharmacology 78 78-83. (doi:10.1111/bcp.12295)

Sun L, Trausch-Azar JS, Muglia LJ \& Schwartz AL 2008 Glucocorticoids differentially regulate degradation of MyoD and Id1 by N-terminal ubiquitination to promote muscle protein catabolism. PNAS $\mathbf{1 0 5}$ 3339-3344. (doi:10.1073/pnas.0800165105)

te Pas MF, de Jong PR \& Verburg FJ 2000 Glucocorticoid inhibition of $\mathrm{C} 2 \mathrm{C} 12$ proliferation rate and differentiation capacity in relation to mRNA levels of the MRF gene family. Molecular Biology Reports 27 87-98. (doi:10.1023/A:1007120921064)

Tintignac LA, Lagirand J, Batonnet S, Sirri V, Leibovitch MP \& Leibovitch SA 2005 Degradation of MyoD mediated by the SCF (MAFbx) ubiquitin ligase. Journal of Biological Chemistry 280 2847-2856. (doi:10.1074/jbc.M411346200)

Trang TT, Viires N \& Aubier M 1992 Effect of steroids on diaphragm of newborn, weanling adolescent, and adult rats. American Review of Respiratory Disease 146 26-31. (doi:10.1164/ajrccm/146.1.26)

Van der Meer SF, Jaspers RT \& Degens H 2011 Is the myonuclear domain size fixed? Journal of Musculoskeletal and Neuronal Interactions $\mathbf{1 1}$ 286-297.

Ward IL \& Weisz J 1984 Differential effects of maternal stress on circulating levels of corticosterone, progesterone, and testosterone in male and female rat fetuses and their mothers. Endocrinology 114 1635-1644. (doi:10.1210/endo-114-5-1635)

Williams MT, Davis HN, McCrea AE, Long SJ \& Hennessy MB 1999 Changes in the hormonal concentrations of pregnant rats and their fetuses following multiple exposures to a stressor during the third trimester. Neurotoxicology and Teratology 21 403-414. (doi:10.1016/ S0892-0362(98)00060-9)

Wilson SJ, Ross JJ \& Harris AJ 1988 A critical period for formation of secondary myotubes defined by prenatal undernourishment in rats. Development 102 815-821.

Woo M, Isganaitis E, Cerletti M, Fitzpatrick C, Wagers A, JimenezChillaron J \& Patti ME 2011 Early life nutrition modulates muscle stem cell number: implications for muscle mass and repair. Stem Cells and Development 20 1763-1769. (doi:10.1089/scd.2010.0349)

Yliharsila H, Kajantie E, Osmond C, Forsen T, Barker DJ \& Eriksson JG 2007 Birth size, adult body composition and muscle strength in later life. International Journal of Obesity 31 1392-1399. (doi:10.1038/ sj.ijo.0803612)

Received in final form 12 December 2016

Accepted 17 January 2017

Accepted Preprint published online 17 January 2017 http://joe.endocrinology-journals.org

DOI: $10.1530 / \mathrm{JOE}-16-0372$
() 2017 Society for Endocrinology Printed in Great Britain 